\title{
Factors influencing mechanical long-term stability of condensation curing silicone elastomers
}

\author{
Juraskova, Alena; Dam-Johansen, Kim; Olsen, Stefan Møller; Skov, Anne Ladegaard
}

Published in:

Journal of Polymer Research

Link to article, DOI:

$10.1007 / \mathrm{s} 10965-020-02272-5$

Publication date:

2020

Document Version

Peer reviewed version

Link back to DTU Orbit

Citation (APA):

Juraskova, A., Dam-Johansen, K., Olsen, S. M., \& Skov, A. L. (2020). Factors influencing mechanical long-term stability of condensation curing silicone elastomers. Journal of Polymer Research, 27(11), [341].

https://doi.org/10.1007/s10965-020-02272-5

\section{General rights}

Copyright and moral rights for the publications made accessible in the public portal are retained by the authors and/or other copyright owners and it is a condition of accessing publications that users recognise and abide by the legal requirements associated with these rights.

- Users may download and print one copy of any publication from the public portal for the purpose of private study or research.

- You may not further distribute the material or use it for any profit-making activity or commercial gain

- You may freely distribute the URL identifying the publication in the public portal

If you believe that this document breaches copyright please contact us providing details, and we will remove access to the work immediately and investigate your claim 


\title{
Factors influencing mechanical long-term stability of condensation curing silicone elastomers
}

\author{
Alena Jurásková ${ }^{1,2}$, Kim Dam-Johansen², Stefan Møller Olsen ${ }^{3}$, Anne Ladegaard Skov ${ }^{1 *}$ \\ ${ }^{I} D P C{ }^{2}$ CoaST, Department of Chemical and Biochemical Engineering, Technical University of Denmark (DTU), \\ Building 229. DK-2800 Kgs Lyngby, Denmark.
}

${ }^{3}$ Hempel A/S, Lundtoftegårdsvej 91, DK-2800 Kgs. Lyngby, Denmark.

*al@kt.dtu.dk, mobile +45 236521 56, fax + 4545882258

\begin{abstract}
This work represents a tutorial overview of necessary considerations, which need to be made when working with condensation curing silicone elastomers. Due to the ability to cure at room temperature, the condensation curing silicone elastomers are commonly used as protective coatings and sealants. Nevertheless, if they are not designed with special precautions, their long-term stability can be negatively influenced. Hereby, we first demonstrate the mechanical long-term stability of different network structures consisting of hydroxyl-terminated polydimethylsiloxanes (HO-PDMS-OH) and methyltrimethoxysilane (MTMS). Even though, the instantaneous mechanical properties of the prepared elastomers are promising, long-term stability tests revealed severe post-curing effects making the overall network properties dynamic. We propose two phenomena explaining the network instability: 1) condensation of unreacted and/or dangling polymer chains, and 2) reaction between the cross-linker molecules. Since the extent of the post-curing reactions is being highly dependent on the stoichiometric ratio between the functional groups of the crosslinker and the polymer $\left(\mathrm{r}=\mathrm{n}_{\mathrm{OCH}} / \mathrm{n}_{\mathrm{OH}}\right)$, the factors influencing the originally calculated $r$ are investigated. Consequently, it is shown how an unfortunate choice of the cross-linker type/purity and the catalyst concentration can significantly influence the original stoichiometric ratio between the functional groups and therefore also the curing reaction and mechanical long-term stability.
\end{abstract}

Keywords: silicone elastomers; condensation chemistry; kinetics; network formation

\section{Introduction}

Silicone elastomers are used in a broad range of applications in electronics ${ }^{1,2}$, medicine ${ }^{3,4}$, automobiles ${ }^{5}$, aerospace ${ }^{6,7}$, and many other industrial fields. The strong covalent bonds between silicium and oxygen and the inherent flexibility of the polymer chains provide silicone networks with most of their favorable properties, such as thermal and oxidative stability, transparency, flexibility, hydrophobicity, and low surface energy. ${ }^{8}$ Yet many potential applications (e.g. protective coatings) remain limited by the low tearing and 
scratch resistance of silicone elastomers. While both the addition of filler and chemical modification of silicone networks are well-established and commonly used methods for enhancing the mechanical properties of silicone elastomers, the mechanical improvement they provide typically causes the deterioration of other favorable properties mentioned above. ${ }^{9}$ One way to improve the mechanical properties of silicone elastomers while minimally affecting their other inherent properties is by creating so called "bimodal" networks. ${ }^{10,11,12}$ Compared to unimodal networks, which consist of polymer chains of uniform length, bimodal networks contain both short and long silicone polymer chains (Figure 1). Bimodal networks can be further divided into homogeneous and heterogeneous types: in homogeneous bimodal networks, short and long chains are homogenously distributed throughout the network; heterogeneous bimodal networks consist of highly crosslinked short-chain clusters (densely cross-linked domains) connected by only a few bonds to the surrounding long-chain network (less densely cross-linked). The loose connection between the short- and long-chain domains causes soft networks to which the addition of the densely cross-linked domains, counterintuitively, reduces stiffness at low strains due to the "liquid-like zone" around the densely cross-linked domains. When stress increases sufficiently, the densely cross-linked domains accommodate some of the strain, as indicated by the pronounced strain-hardening behavior of these networks. ${ }^{10}$

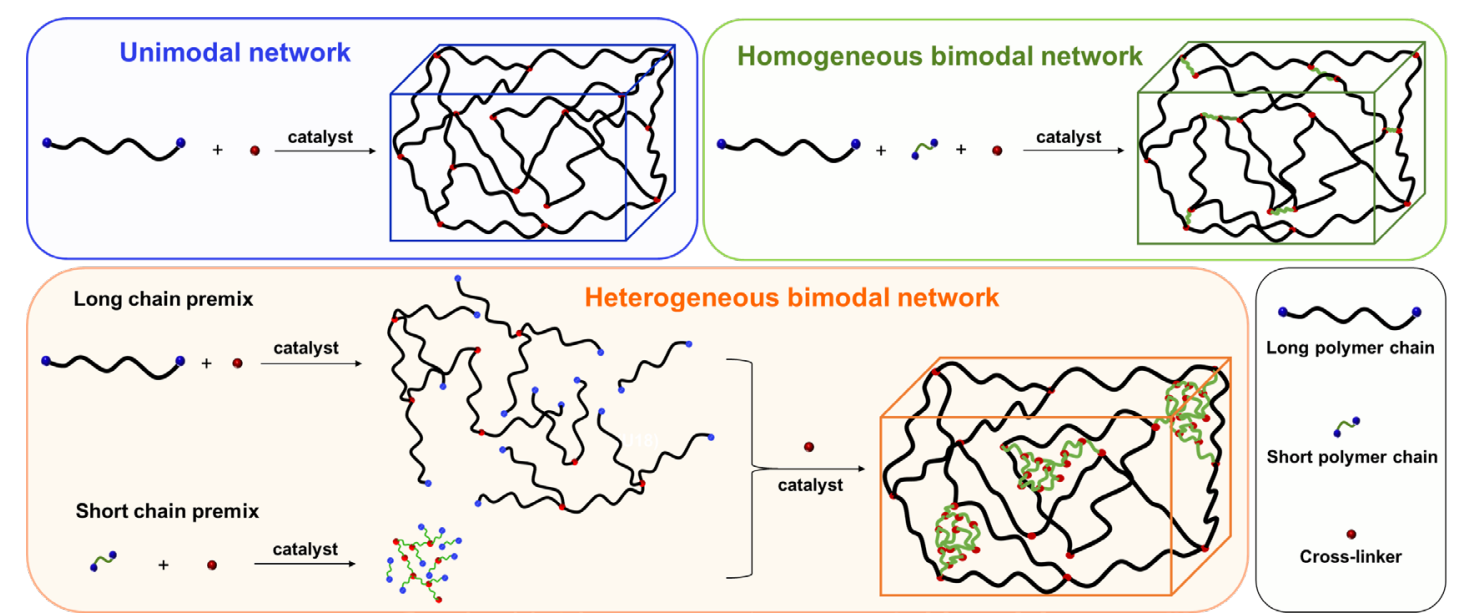

Figure 1: Schematics of the preparation procedure for different network structures. a) Unimodal network prepared by reaction between polymer chains of one length with cross-linker. b) Homogeneous bimodal network prepared by reaction between short polymer chains, long polymer chains, and cross-linker. c) The heterogeneous bimodal network consists of the same components as the homogeneous bimodal network, but is prepared via a two-step synthesis: first, hyper-branched structures are synthetized by reactions of long chains with deficient amounts of cross-linker and short chains with similarly deficient amounts of crosslinker; second, the hyper-branched structures are reacted together with additional cross-linker.

The beneficial effects of the structural bimodality, particularly of the heterogeneous bimodal networks, were reported by Bejenariu et al. ${ }^{12}$ and Madsen et $\mathrm{al}^{10}$. In both studies, addition curing silicone elastomers were 
used to prepare the different network structures. Addition curing silicone elastomers are usually synthetized by hydrosilylation reaction between a telechelic vinyl-terminated polydimethylsiloxane and a hydrosilane or a hydrosiloxane cross-linker in presence of a platinum catalyst (Figure 2a). Nevertheless, some applications are limited by the expensive and inhibition prone Pt catalyst, as well as by the required high curing temperature. ${ }^{13,14,15}$ For these applications, condensation curing silicone elastomers, commonly prepared by reaction between a telechelic hydroxyl-terminated polydimethylsiloxane (HO-PDMS-OH) and an alkoxysilane cross-linker in presence of a tin catalyst and humidity (Figure2b), are prefered. ${ }^{16,8}$

a)

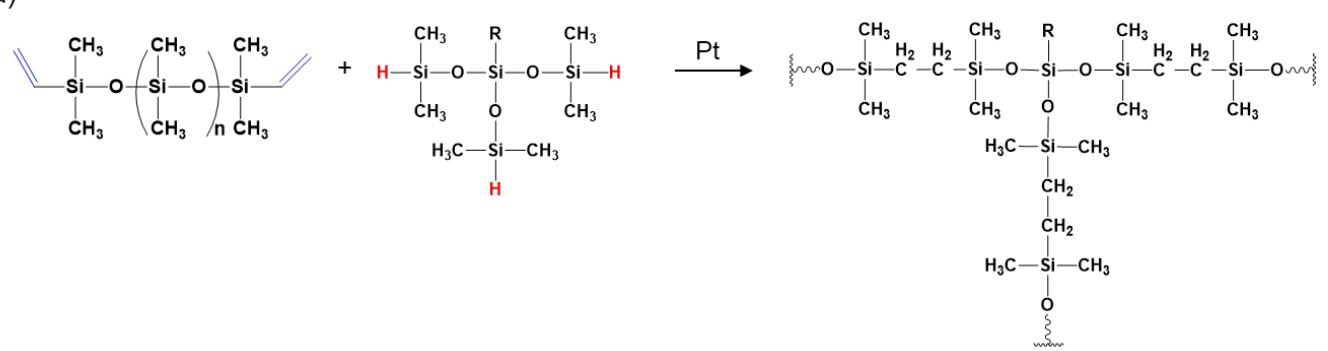

b)

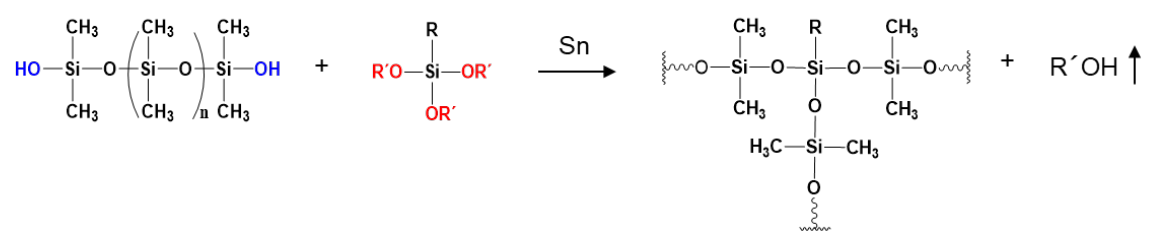

Figure 2: Example of silicone elastomer preparation by a) hydrosilylation reaction between a telechelic vinyl-terminated PDMS and hydrosilane; b) condensation reaction between a telechelic hydroxyl-terminated polydimethylsiloxane and alkoxysilane.

In this work, we first focus on the mechanical properties of different networks structures prepared by reaction of HO-PDMS-OH with MTMS cross-linker in the presence of Sn catalyst. Because the investigation of the different network structures' mechanical properties found poor or minimal reproducibility, a long-term stability study of was initiated. It was clear that the usual, simplistic description of condensation curing shown in Figure 3 did not accurately describe our results, which included significant post-curing phenomena not explained by either residual solvent or by simple reaction between alkoxy (-OR) and hydroxyl (-OH) functional groups. In fact, the long-term stability study demonstrated significant age-dependent changes of the mechanical properties regardless of initial network structure. Subsequent analysis revealed the importance of several factors potentially influencing network (in)stability in condensation cured silicone elastomers, which are thoroughly discussed in this manuscript. 


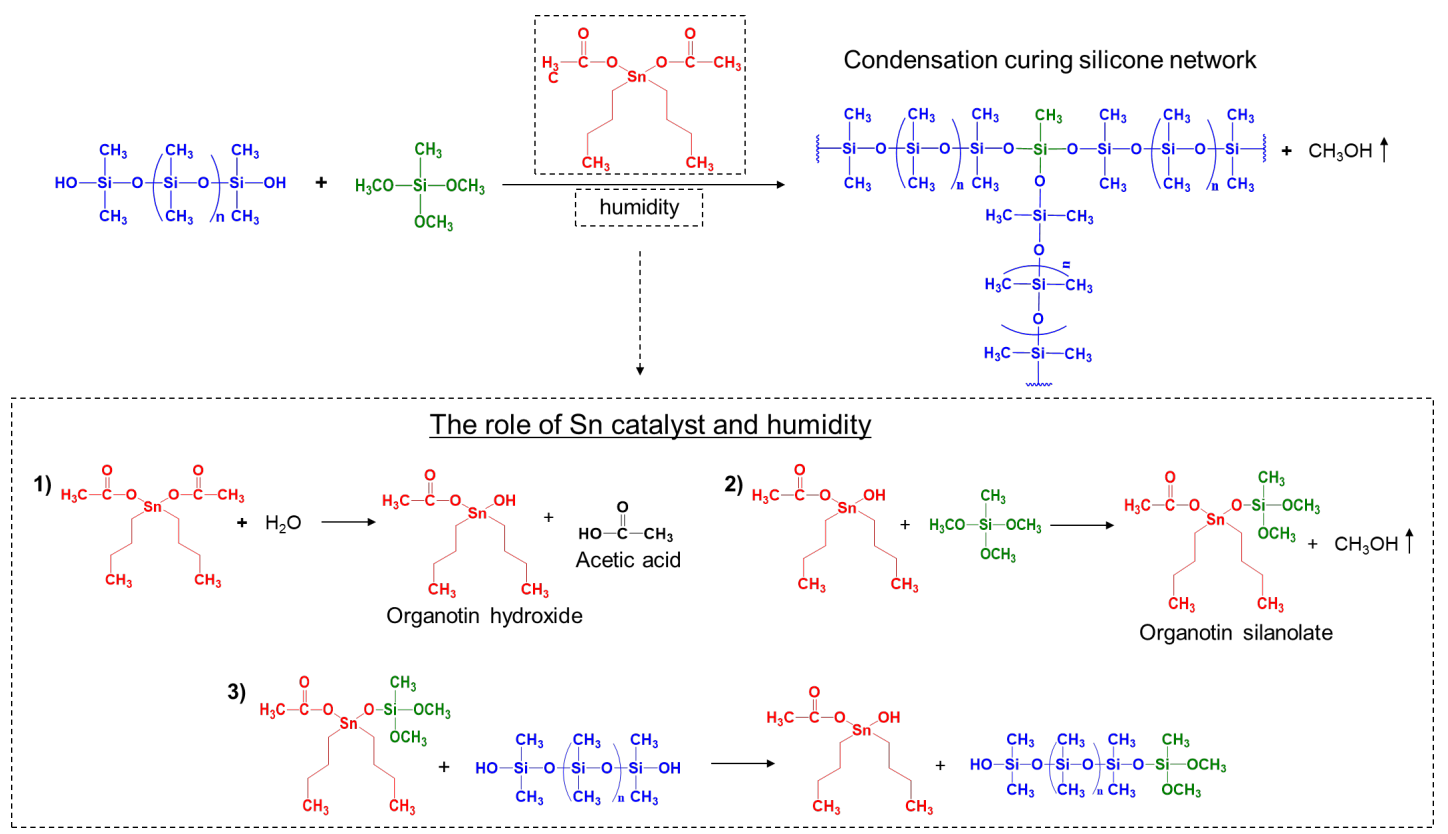

Figure 3: Condensation reaction between HO-PDMS-OH and MTMS in the presence of dibutyltin-diacetate, leading to the creation of a silicone network with $\mathrm{CH}_{3} \mathrm{OH}$ as a side product. The tin catalyst mediates the reaction between the $-\mathrm{OH}$ groups of the $\mathrm{HO}-\mathrm{PDMS}-\mathrm{OH}$ and the $-\mathrm{OCH} 3$ groups of the MTMS via a mechanism that can be divided into three reaction steps: ${ }^{17}$ 1) the tin catalyst is hydrolyzed to organotin hydroxide; 2) the organotin hydroxide reacts with the MTMS to create organotin silanolate; 3) the organotin silanolate reacts with HO-PDMS-OH, causing linkage between the polymer and the cross-linker.

\section{Experimental}

\subsection{Materials}

Dibutyltin-diacetate catalyst (Sn catalyst), methyltrimethoxysilane cross-linker 1 (MTMS1), and hydroxylterminated polydimethylsiloxane - 40cSt $\left(\mathrm{M}_{\mathrm{n}} \sim 1000 \mathrm{~g} / \mathrm{mol}\right)$ were kindly provided by Sika AG. Hydroxyterminated polydimethylsiloxanes-PMX-0156 $\left(\mathrm{M}_{\mathrm{n}} \sim 4000 \mathrm{~g} / \mathrm{mol}\right)$ and $\mathrm{C} 2 \mathrm{~T}\left(\mathrm{M}_{\mathrm{n}} \sim 18000 \mathrm{~g} / \mathrm{mol}\right)$ were obtained from Dow Corning and Wacker Chemie, respectively. Methyltrimethoxysilane cross-linker 2 (MTMS2) was purchased from Gelest Inc. Hostaphan RN 190/190 $\mu \mathrm{m}$ (polyester plastic carrier) was purchased from Mitsubishi Polyester Film.

\subsection{Preparation of different network structures precursors}

The masses of the components used for preparation of silicone elastomer network precursors are summarized in Table 1. The different networks structures were prepared as follows: 


\section{Unimodal network}

HO-PDMS-OH (C2T), cross-linker (MTMS1) and Sn catalyst were used to prepare the unimodal network (U18). The components were mixed in the FlackTech speed mixer according to the scheme illustrated in Figure 4a. The MTMS1 cross-linker was used in excess, with stoichiometric imbalance between the functional groups: $r=5$, where $r=n_{\mathrm{OCH} 3(\mathrm{MTMS})} / \mathrm{n}_{\mathrm{OH}(\mathrm{C} 2 \mathrm{~T})}$. The catalyst was used in the concentration of $1 \mathrm{wt} \%$.

\section{Homogeneous bimodal networks}

Two different homogeneous bimodal networks (B.4.18 and B.1.18) were prepared by mixing long chain HOPDMS-OH (C2T), short chain HO-PDMS-OH (PMS-0156 and 40cSt, respectively), cross-linker (MTMS1), and Sn catalyst according to the scheme illustrated in Figure 4b. The mass ratio of the long and short chain fractions was 90:10. The MTMS1 cross-linker was used in excess, with stoichiometric imbalance between

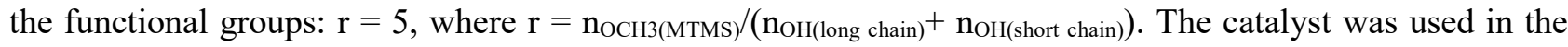
concentration of $1 \mathrm{wt} \%$.

\section{Heterogeneous bimodal networks}

For the preparation of the heterogeneous bimodal networks, firstly long chain premix (premix C2T) and two short chain premixes (premix PMS-0156 and premix 40cSt) were prepared following the scheme illustrated in Figure 4a. The MTMS1 cross-linker was used in stoichiometric amounts $(r=1)$, in contrast to the preparations listed above. This value was chosen in order to prevent full crosslinking of the premixes. The Sn catalyst was used in the concentration of $0.2 \mathrm{wt} \%$ for the short chain premixes and $0.1 \mathrm{wt} \%$ for the long chain premix to allow for slow reaction only. The premixes were covered by aluminum foil with small holes and pre-cured in a humidity oven. After 3 days of pre-reaction, each premix was mixed using the speed mixer for $0.5 \mathrm{~min}$ at $2000 \mathrm{rpm}$, after which they were ready for the heterogeneous bimodal network preparation. The two different heterogeneous bimodal networks (HetB.4.18 and HetB.1.18) were then prepared by mixing the long chain premix (premix C2T) and short chain premix (premix PMS-0156 and premix 40cSt, respectively) together with the addition of MTMS1 and Sn catalyst, following the mixing order given in Figure 4c. The mass ratio between the long and short chain premixes was 90:10. The amount of additional cross-linker was calculated to give an overall stoichiometric ratio: $\mathrm{r}=5$, where $\mathrm{r}=\mathrm{n}_{\mathrm{OCH}(\mathrm{MTMS})} /\left(\mathrm{n}_{\mathrm{OH}(\text { long chain })}+\mathrm{n}_{\mathrm{OH}(\text { short chain })}\right)$. The Sn catalyst was added in the concentration of $0.1 \mathrm{wt} \%$. 
a)

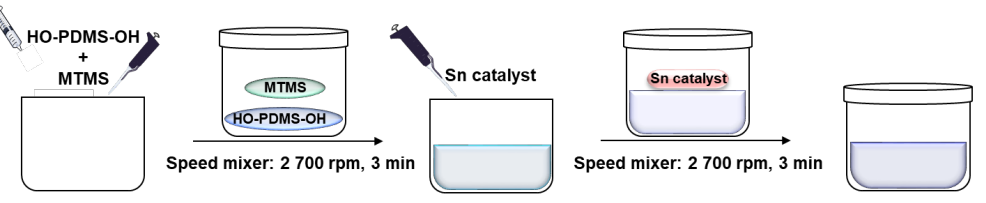

b)
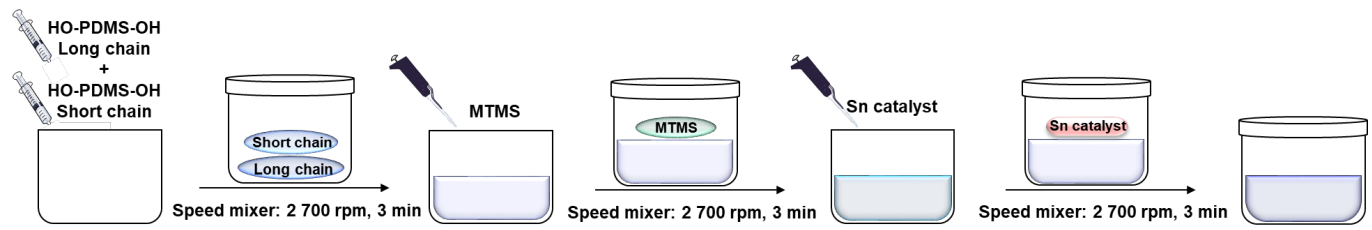

c)
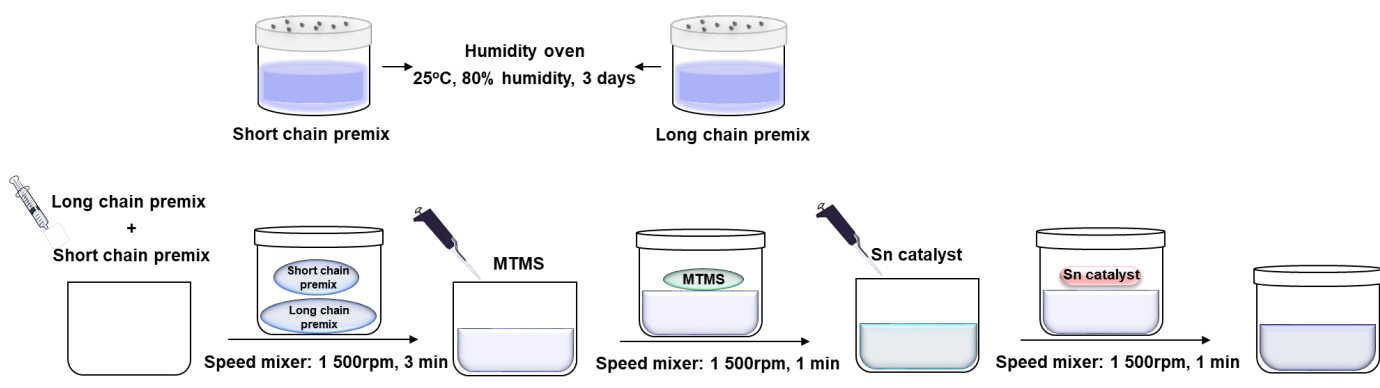

Figure 4: Mixing order of the different network structure components. a) Unimodal network precursor, and short and long chain premixes, were prepared by mixing HO-PDMS-OH and MTMS, followed by addition of Sn catalyst. b) Homogeneous bimodal network precursors were prepared by mixing short and long HOPDMS-OH chains, followed by addition of MTMS cross-linker and Sn catalyst. c) Heterogeneous bimodal network precursors were prepared by mixing short and long chain premixes (prepared in step a)), followed by addition of MTMS cross-linker and Sn catalyst.

Table 1: Silicone elastomer network precursor compositions.

\begin{tabular}{|c|c|c|c|c|c|}
\hline \multicolumn{6}{|c|}{ Unimodal silicone network precursor composition } \\
\hline Sample name & \multicolumn{2}{|c|}{$\mathrm{C} 2 \mathrm{~T}$} & \multicolumn{2}{|c|}{ MTMS (r=5) } & Sn catalyst $(1 \mathrm{wt} \%)$ \\
\hline U.18 & \multicolumn{2}{|c|}{$5 \mathrm{~g}$} & \multicolumn{2}{|c|}{$0.1261 \mathrm{~g} / 132 \mu 1$} & $0.0513 \mathrm{~g} / 39 \mu \mathrm{l}$ \\
\hline \multicolumn{6}{|c|}{ Homogeneous bimodal silicone network precursor composition } \\
\hline Sample name & $\mathrm{C} 2 \mathrm{~T}$ & PMX-0156 & $40 \mathrm{cSt}$ & MTMS ( $\mathrm{r}=5)$ & Sn catalyst $(1 \mathrm{wt} \%)$ \\
\hline B.4.18 & $4.5 \mathrm{~g}$ & \multirow[t]{2}{*}{$0.5 \mathrm{~g}$} & 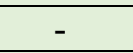 & $0.1362 \mathrm{~g} / 143 \mu 1$ & $0.0414 \mathrm{~g} / 31 \mu \mathrm{l}$ \\
\hline B.1.18 & $4.5 \mathrm{~g}$ & & $0.5 \mathrm{~g}$ & $0.3406 \mathrm{~g} / 357 \mu 1$ & $0.0534 \mathrm{~g} / 41 \mu 1$ \\
\hline \multicolumn{6}{|c|}{ Long chain premix composition } \\
\hline Premix name & \multicolumn{2}{|c|}{$\mathrm{C} 2 \mathrm{~T}$} & \multicolumn{2}{|c|}{ MTMS (r=1) } & Sn catalyst $(0.1 \mathrm{wt} \%)$ \\
\hline $\mathrm{C} 2 \mathrm{~T}$ & \multicolumn{2}{|c|}{$20 \mathrm{~g}$} & \multicolumn{2}{|c|}{$0.1009 \mathrm{~g} / 106 \mu 1$} & $0.0201 \mathrm{~g} / 15 \mu \mathrm{l}$ \\
\hline \multicolumn{6}{|c|}{ Short chain premix composition } \\
\hline Premix name & PMX-0156 & $40 \mathrm{cSt}$ & \multicolumn{2}{|c|}{ MTMS (r=1) } & Sn catalyst $(0.2 \mathrm{wt} \%)$ \\
\hline PMX-0156 & $10 \mathrm{~g}$ & - & \multicolumn{2}{|c|}{$0.2270 \mathrm{~g} / 238 \mu 1$} & $0.0205 \mathrm{~g} / 16 \mu \mathrm{l}$ \\
\hline $40 \mathrm{cSt}$ & - & $10 \mathrm{~g}$ & & $1 \mathrm{~g} / 951 \mu \mathrm{l}$ & $0.0218 \mathrm{~g} / 17 \mu 1$ \\
\hline \multicolumn{6}{|c|}{ Heterogeneous bimodal silicone network precursor composition } \\
\hline Sample name & $\begin{array}{c}\mathrm{C} 2 \mathrm{~T} \\
\text { premix }\end{array}$ & $\begin{array}{l}\text { PMX-0156 } \\
\text { premix }\end{array}$ & $\begin{array}{l}\text { 40cSt } \\
\text { premix }\end{array}$ & $\begin{array}{c}\text { MTMS } \\
\text { (overall } \mathrm{r}=5 \text { ) }\end{array}$ & Sn catalyst $(0.1 \mathrm{wt} \%)$ \\
\hline
\end{tabular}




\begin{tabular}{|c|c|c|c|c|c|}
\hline HetB.4.18 & $4.5272 \mathrm{~g}$ & $0.5124 \mathrm{~g}$ & - & $0.1362 \mathrm{~g} / 143 \mu \mathrm{l}$ & $0.0052 \mathrm{~g} / 3.9 \mu \mathrm{l}$ \\
\hline HetB.1.18 & $4.5272 \mathrm{~g}$ & - & $0.5465 \mathrm{~g}$ & $0.2724 \mathrm{~g} / 285 \mu \mathrm{l}$ & $0.0053 \mathrm{~g} / 4.0 \mu \mathrm{l}$ \\
\hline
\end{tabular}

\subsection{Silicone film preparation and curing procedure}

The silicone network precursors, preparation of which is described above, were coated into thin films on a polyester carrier using a coating knife with a coating height of $200 \mu \mathrm{m}$ (Figure 5). To ensure homogeneous thickness of the silicone films, an automatic film applicator (Elcometer 4340 Automatic Film Applicator) was used to move the coating knife. The film applicator was set to the lowest possible speed, which is approximately $5 \mathrm{~mm} / \mathrm{s}$. The samples were subsequently cured for 4 days in a humidity oven at $25^{\circ} \mathrm{C}$ and $80 \%$ relative humidity.

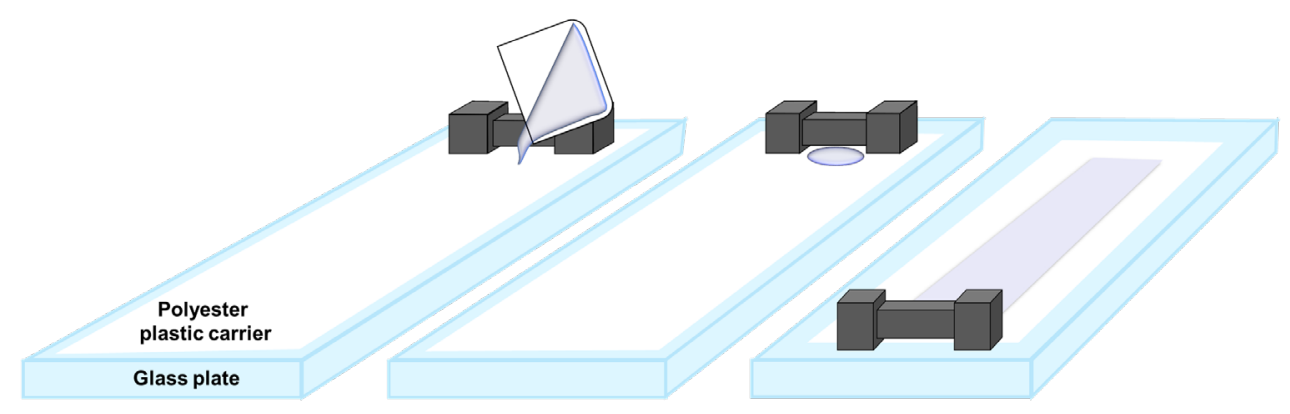

Figure 5: Silicone film preparation by coating the silicone elastomer precursors onto a polyester plastic carrier.

\subsection{MTMS evaporation tests}

To investigate the influence of sample thickness on the curing process, evaporation tests were conducted. A mixture of C2T, MTMS1 $(r=5,2.6 \mathrm{wt} \%)$ and Sn catalyst $(1 \mathrm{wt} \%)$ was prepared following the description for unimodal network preparation in Section 2.2. To obtain final silicone elastomer of different thicknesses, the mixture was then poured into aluminium cups in the following amounts: $0.15 \mathrm{~g}, 0.5 \mathrm{~g}, 1 \mathrm{~g}, 1.5 \mathrm{~g}, 2 \mathrm{~g}$, and $3 \mathrm{~g}$. The weight loss of the samples over time was then measured using an analytical balance. Approximate sample thicknesses were calculated as $t_{\text {sample }}=t_{\text {Alcup+sample }}-t_{\text {Alcup }}$. The thicknesses were measured with a coating thickness meter (MEGA-CHECK Pocket FE). The same procedure was repeated with a mixture of C2T, MTMS2 ( $r=5,2.6 \mathrm{wt} \%)$ and Sn catalyst ( $1 \mathrm{wt} \%)$ to investigate the influence of cross-linker purity.

\subsection{Condensation of HO-PDMS-OH}

Five mixtures consisting of $5 \mathrm{~g}$ of $\mathrm{C} 2 \mathrm{~T}$ and $0.05,0.1,0.5,1$, and $1.5 \mathrm{wt} \%$ of $\mathrm{Sn}$ catalyst, respectively, were mixed in the FlackTech speed mixer and subsequently covered by aluminum foil with small holes. The extent of $\mathrm{C} 2 \mathrm{~T}$ condensation in the presence of Sn catalyst was assessed via increase in molecular weight using size-exclusion chromatography. 


\subsection{Characterization}

Mechanical properties were tested by ARES-G2 rheometer using SER geometry. A sample $25 \mathrm{~mm}$ in length and $6 \mathrm{~mm}$ in width was placed between two drums separated by a distance of $12.7 \mathrm{~mm}$ (Figure 6a). The test specimen was elongated uniaxially at a steady Hencky strain rate $\left(\dot{\epsilon}_{H}\right)$ of $0.01 \mathrm{~s}^{-1}$ until failure occurred at the middle of the sample. All measurements were performed at room temperature. The stressstrain curves were calculated using the following equations:

$$
\begin{aligned}
& \epsilon_{H}=\dot{\epsilon}_{H} \cdot t=\ln \left(\frac{l}{l_{o}}\right) \\
& \gamma=\frac{l-l_{o}}{l_{o}}=\left(e^{\epsilon_{H}}-1\right) \\
& \sigma=\frac{F}{d \cdot w}
\end{aligned}
$$

where $\epsilon_{H}$ is Hencky strain, $t$ is step time, 1 is length of deformed sample, $1_{0}$ is initial sample length, $\gamma$ is strain, $\sigma$ is engineering stress, $\mathrm{F}$ is force, $\mathrm{d}$ is sample thickness, and $\mathrm{w}$ is sample width.

Film thickness was measured in three to five different places on the silicone elastomer film sheet and then averaged to give the stated thickness. A small rectangular specimen was placed on the edge of a microscope glass slide (Figure 6b), which was then placed under an optical microscope (LEICA DM LB microscope) to determine the thickness.

The Young's modulus was determined from the tangent of the linear region of the stress-strain curve at low strain (up to approximately $20 \%$ of the strain).

The standard deviation was calculated from five tensile measurements for each sample composition.

a)

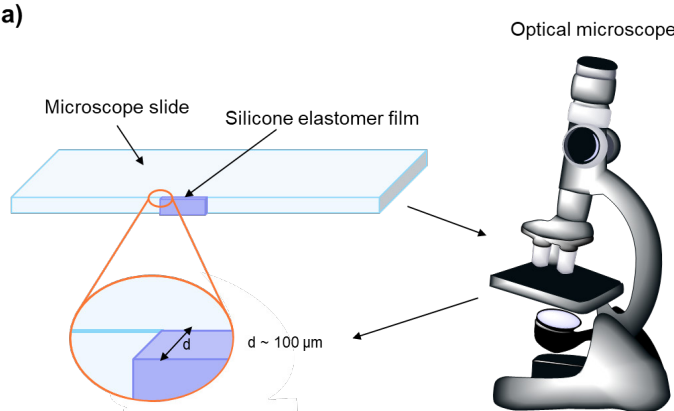

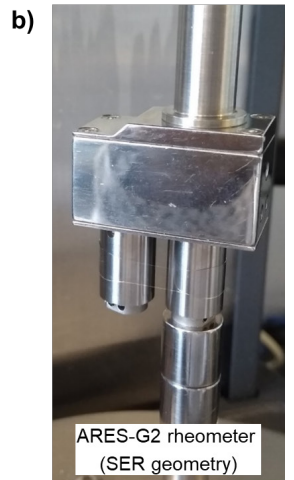

b) (SER geometry)

Figure 6: Illustration of sample placement on a) a microscope glass slide to measure film thickness; b) ARES-G2 rheometer with SER geometry to assess stress-strain properties.

Long-term stability of the silicone elastomers was evaluated via the measured changes over time in both elongation at break and Young's modulus. Samples were kept in a humidity oven under constant conditions of $80 \%$ relative humidity at $25^{\circ} \mathrm{C}$ and measured over a period of six months using ARES-G2 rheometer with SER geometry as described above. 
Proton nuclear magnetic resonance ( ${ }^{1}$ H-NMR) characterization was performed on a 7 Tesla SpectrospinBruker AC 300MHz spectrometer at room temperature using deuterated solvent chloroform-d.

Size-exclusion chromatography (SEC) was performed on a TOSOH EcoSEC HLC-8320GPC system equipped with an EcoSEC RI detector. This system was fitted with two SDV LINEAR S $5 \mu \mathrm{m} 8 \times 300 \mathrm{~mm}$ columns in series, protected by a GUARD column (SDV $5 \mu \mathrm{m} 8 \times 50 \mathrm{~mm}$ ), all supplied by PSS. Samples were run in toluene at $35^{\circ} \mathrm{C}$. Molar mass characteristics were calculated using PSS WinGPC Unity, Build 9350 software, and linear PDMS standards acquired from PSS.

\section{Results and discussion}

\subsection{Unimodal and bimodal networks}

All network structures were prepared using an excess of MTMS1 cross-linker $r=5$, where the stoichiometric ratio is given by $\mathrm{r}=\mathrm{n}_{\mathrm{OCH}} / \mathrm{n}_{\mathrm{OH}}$. The stoichiometry used was based on a previous, unpublished study conducted by our group, in which it revealed sufficient curing combined with the best instantaneous mechanical properties. After 4 days of curing in a high humidity oven, uniform films with non-stick surfaces were obtained, and the curing was considered complete. The stress-strain curves of unimodal and homogeneous bimodal networks in Figure 7 show that implementing short chains has a significant effect on the Young's modulus as well as on ultimate stress and strain properties. The unimodal network (U.18) possesses lower Young's modulus $(0.18 \mathrm{MPa})$ and higher ultimate stress and strain properties compared to the homogeneous bimodal networks. Decreasing the chain length in the homogeneous bimodal networks (B.4.18 and B.1.18) significantly increases the Young's modulus from 0.20 MPa for B.4.18 to 0.34 MPa for B.1.18, an effect which can be ascribed to the limited extensibility of the short chains. Unlike in addition curing silicone elastomers, which, according to Bejenariu et al. ${ }^{12}$, experienced tearing of the unimodal elastomer films upon handling, both condensation curing unimodal and homogeneous bimodal silicone elastomer films were easy to handle without tearing. 

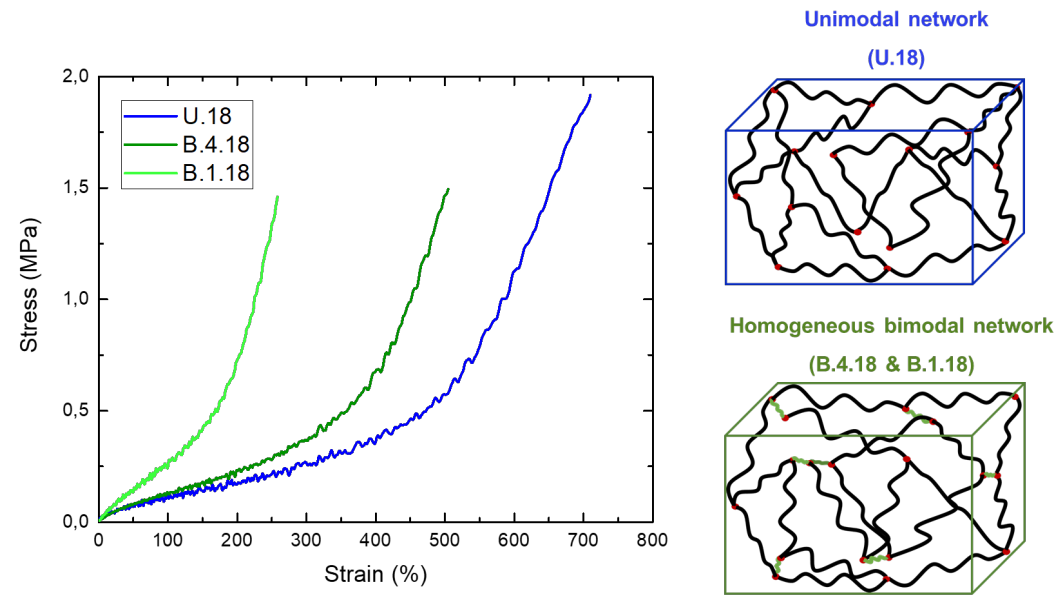

Figure 7: Stress-strain properties of unimodal (U.18) and homogeneous bimodal (B.4.18 and B.1.18) networks.

After the initial study on unimodal and homogeneous bimodal networks, we moved to the preparation of heterogeneous bimodal networks. Other studies have shown that heterogeneous bimodal networks prepared by addition curing chemistry possess low modulus combined with low viscous dissipation, indicating a high degree of crosslinking. ${ }^{10,12}$ This behavior has been attributed to the advanced microstructure of the networks, which consists of highly cross-linked short chain domains (micrometer sized) within the long chain network. ${ }^{10}$ It was therefore hypothesized that this technique could be directly applied to condensation curing silicone elastomers. Unlike most addition curing silicone elastomers, condensation curing silicone elastomers can be cured efficiently at room temperature in open air, which is advantageous for many applications. Condensation curing chemistry would therefore allow a much more widespread use of heterogeneous bimodal networks: e.g., for coating applications. Nevertheless, the mechanical properties of heterogeneous bimodal networks synthesized via condensation chemistry exhibited poor reproducibility. Long-term stability test of the network structures was therefore conducted by evaluating changes in Young's modulus and elongation at break over time. This resulted in the finding that none of the network structures prepared in this study display long-term stability. Figure 8 shows an example of the stability test for unimodal (U.18) and homogeneous bimodal (B.1.18 and B.4.18) networks, in which it can be seen that elongation at break decreases with sample age while Young's modulus increases. These results forced us to revise our preparation of the different network structures. The rest of this work is therefore concentrated on a fundamental study of condensation curing silicone elastomers. The main focus is then paid to the explanation of the network instability in the sense that post-curing effects by far dominate the overall properties as illustrated by the five-fold increase in the Young's modulus of the different samples over the course of six months (Figure 8). 

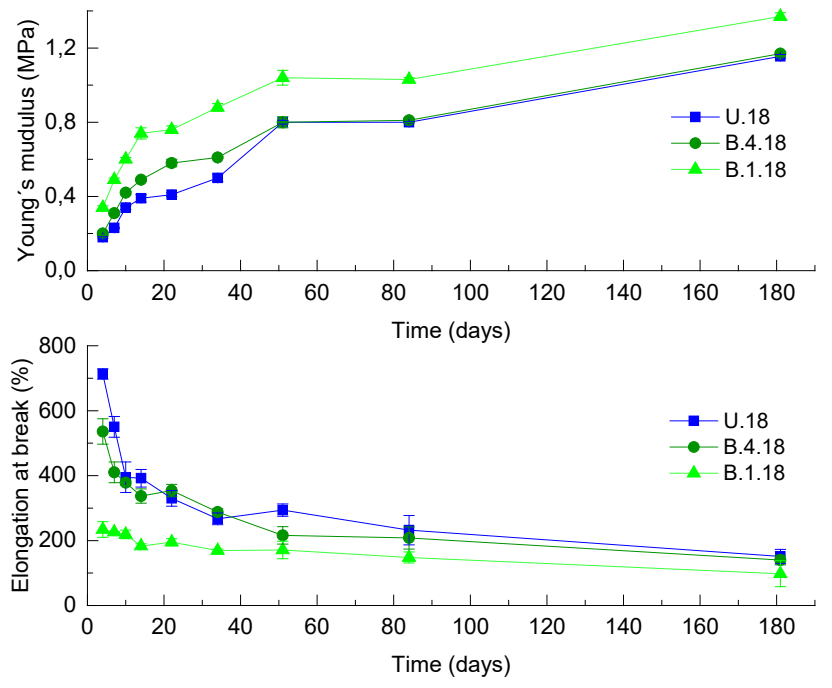

Figure 8: Stability of unimodal (U.18) and bimodal (B.4.18 \& B.1.18) condensation curing silicone networks presented by changes in the absolute values of elongation at break and Young's modulus over time. Sample thickness was $\sim 100 \mu \mathrm{m}$.

\subsection{Stability of condensation curing silicone elastomers}

As we have demonstrated above, even the unimodal silicone network formed via condensation chemistry (U.18) is unstable over time. Two hypothesis for the increasing Young's modulus and decreasing elongation at break with sample age can be established:

\section{Reaction between the cross-linker molecules}

Since the MTMS1 cross-linker is used in significant excess (five times the theoretically required stoichiometry), a low-density network with many unreacted groups of the cross-linker is initially created (Figure 9.1), possessing low Young's modulus and high extensibility. Nevertheless, the reaction between the cross-linker molecules does eventually take place, creating silica domains and increasing the Young's modulus while decreasing the elongation at break due to this denser network structure.

\section{Reaction between the hydroxyl groups of the HO-PDMS-OH}

Despite the excess MTMS1 cross-linker used, it is possible that its volatility results in an actual deficiency of the cross-linker in the film, thus preventing full curing of the network. In this case, an excess of hydroxyl groups from the HO-PDMS-OH would be present in the system. Clarson et al. ${ }^{18}$ have reported that a condensation reaction between the HO-PDMS-OH takes place in the presence of tin 2-ethylhexanoate in concentrations above $0.1 \mathrm{wt} \%$. Because the concentration of dibutyltin-diacetate catalyst used in this study is $1 \mathrm{wt} \%$, the condensation reaction between the HO-PDMS-OH cannot be ruled out. The network instability caused by this phenomenon can be explained as follows: first, a network with a significant fraction of 
dangling OH-terminated PDMS chains is created, since the reaction between HO-PDMS-OH and MTMS is still expected to be the fastest reaction under the given conditions (Figure 9.2). These initial dangling chains act as a plasticizer, resulting in low Young's modulus and high elongation at break. The unreacted hydroxyl groups condensate over time, which causes an increase in the Young's modulus due to the increased crosslinking density and thereby also decreases the elongation at break, which is usually inversely related to the Young's modulus.
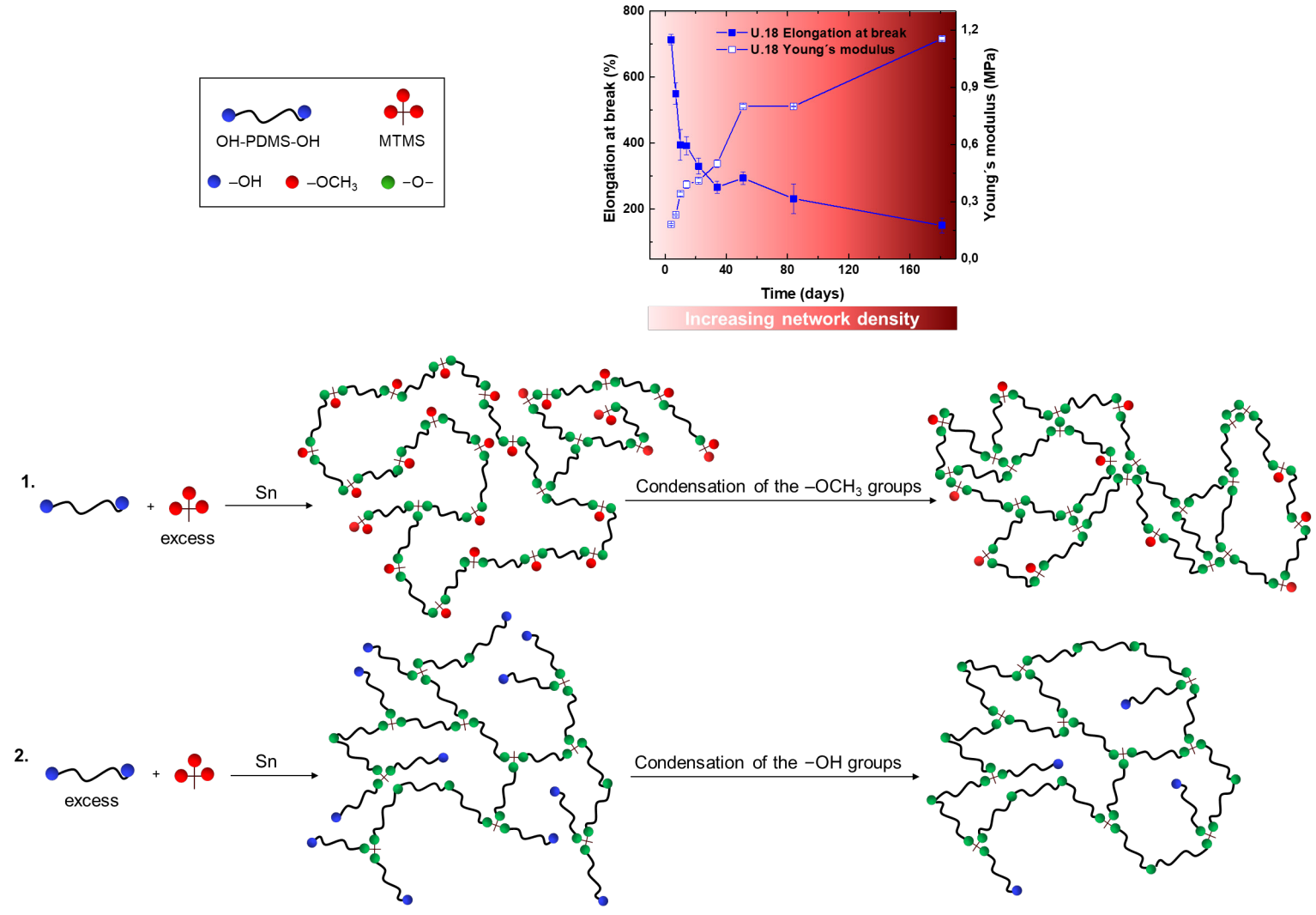

Figure 9: Two possible phenomena leading to increasing network density of condensation curing silicone elastomers over time. Depending on the initial stoichiometry, a network is initially created from the reaction of $-\mathrm{OH}$ and $-\mathrm{OCH}_{3}$, which is then followed by much slower reactions such as: (1) condensation of the $\mathrm{OCH}_{3}$ groups, or (2) condensation of the $-\mathrm{OH}$ groups.

\subsection{Design of stable networks}

The above discussion of the phenomena potentially leading to silicone elastomers' 'long-term instability' makes it clear that several parameters must be considered when working with condensation curing silicone elastomers. In general, the type, concentration, and purity of the cross-linker, catalyst concentration, curing environment, and sample dimensions (thickness) can significantly affect the properties of the silicone network in both the short- and long-term. While some of these factors have been previously pointed out by 
other research groups, ${ }^{18,19}$ a comprehensive overview of all the necessary considerations when working with condensation curing silicone elastomers is missing from the literature. To provide such an overview, we present our own various mistakes in the preparation of the silicone networks and bring a small summary on what must be considered while working with condensation curing silicone elastomers.

\subsubsection{Curing agent}

A broad range of cross-linkers can be used for condensation curing chemistry. ${ }^{20}$ The most commonly reported in the literature are silanes with three or four alkoxy-functional groups, such as methyltrimethoxysilane, tetraethoxysilane, and vinyltriethoxysilane. Nevertheless, when working with these low molecular weight cross-linkers the samples should be covered during curing to prevent cross-linker loss. If the curing needs to be carried out in open air-e.g., due to application requirements-special precautions must be taken regarding both sample thickness and cross-linker concentration, as cross-linker volatility means that the curing will be dependent on the sample thickness. Of course, from an environmental point of view, using cross-linkers with low volatility is preferable in order to fully avoid evaporation and thereby lower the volatile organic content (VOC) of the material produced.

Figure 10 summarizes results of an evaporation study, which was conducted to quantify the volatility of MTMS1 cross-linker when mixed with $\mathrm{C} 2 \mathrm{~T}$ and Sn catalyst. Despite the fact that all samples possessed no sticky surfaces within a few hours of curing —indicating a reaction far beyond the gelation threshold—-the recorded sample weight losses can be seen to significantly increase with decreasing sample thickness. This is partially a result of the slow migration of the condensation curing side product (methanol) to the sample surface. Nevertheless, based on the initial MTMS1 concentration used for sample preparation, the weight loss caused by methanol should theoretically be $\sim 1.8 \mathrm{wt} \%$. This value is lower than the actual weight loss $(2.5 \mathrm{wt} \%)$ for the $\sim 0.2 \mathrm{~mm}$ thick sample, suggesting evaporation of MTMS1 cross-linker molecules. Due to the cross-linker volatility, the original stoichiometric ratio between the reactive groups of the cross-linker and the polymer is eventually altered in a sample thickness-dependent manner as well as becoming nonuniform throughout individual samples. The significant volatility of the MTMS1 observed for the sample with thickness $\sim 0.2 \mathrm{~mm}$ suggests that the instability of the silicone elastomer films U18, B.4.18 and B.1.18 (Figure 8 ) is caused by the mechanism proposed in Figure 9.2. 


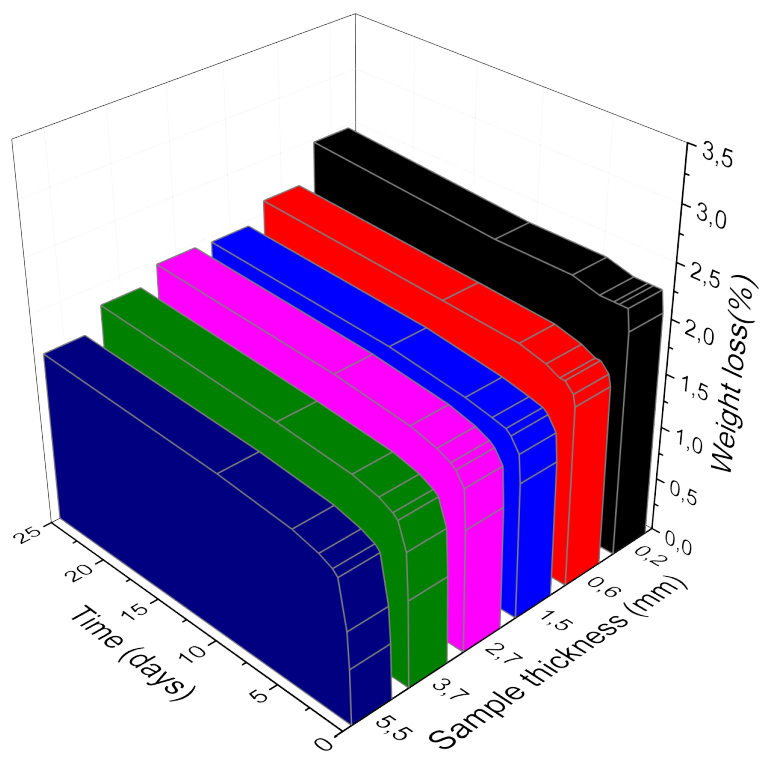

Figure 10: 3D plot of the dependence of sample weight loss over time on sample thickness. Sample thickness was varied from 0.2 to $5.5 \mathrm{~mm}$. The samples consisted of C2T, MTMS1 (2.5wt\%), and Sn catalyst $(1 \mathrm{wt} \%)$.

As outlined above, low molecular weight silane cross-linkers do not perform optimally if the final application does not allow coverage of the substrate during curing. In addition, as illustrated in Figure 11, low molecular weight alkoxysilanes are prone to hydrolysis-condensation reaction. ${ }^{21,22,23}$ The hydrolysiscondensation reaction leads to an increase of the number of reactive groups per cross-linker molecule and thereby also per volume, which needs to be taken into consideration when formulating.

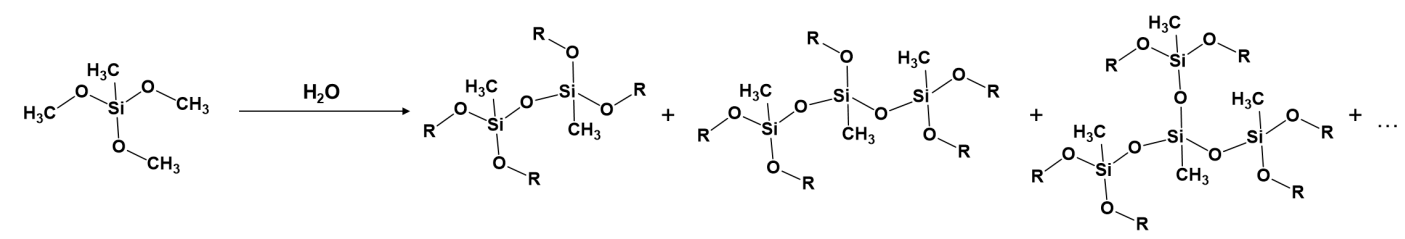

Figure 11: Hydrolysis-condensation reaction of MTMS cross-linker leading to a mix of higher molecular weight silanes, where $\mathrm{R}$ represents $-\mathrm{OCH} 3$ or $-\mathrm{OH}$ groups.

${ }^{1} \mathrm{H}$ NMR analysis showed that the MTMS1 cross-linker indeed contained hydrolysis-condensation products (Figure 12), as the integration of the $-\mathrm{OCH}_{3}$ signal is much lower than the theoretical value for a pure MTMS molecule. This affects both the volatility and the average number and type of functional groups per molecule. 


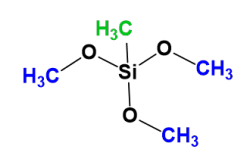

$0: 03: 9$
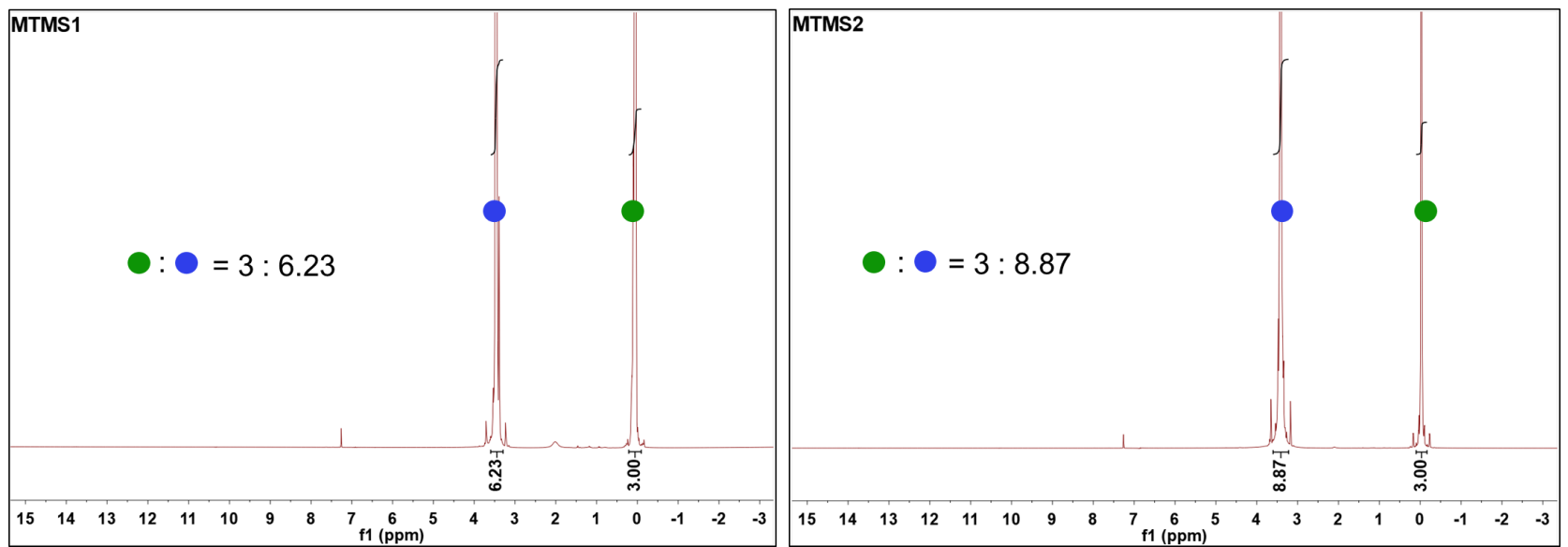

Figure 12: On the left, ${ }^{1} \mathrm{H}$ NMR spectra of the MTMS1 cross-linker, where the hydrolysis-condensation reaction took place. On the right, ${ }^{1} \mathrm{H}$ NMR spectra of the MTMS2 cross-linker, which consists mainly of unreacted methyltrimethoxysilane molecules.

In order to investigate the effect of cross-linker purity on the curing reaction, the volatility experiment was repeated using cross-linker MTMS2, which was purchased in high purity as confirmed by ${ }^{1} \mathrm{H}-\mathrm{NMR}$ spectroscopy (Figure 12).

The 3D plot in Figure 13 shows that the weight loss of samples cross-linked by MTMS2 is much higher than that of samples cross-linked by MTMS1. In addition, samples of thickness $\leq 0.6 \mathrm{~mm}$ did not cure and samples of thickness $\geq 1.5 \mathrm{~mm}$ remained sticky on the surface (Figure 14), illustrating the significant influence which cross-linker purity exerts on the curing reaction. Unlike the cross-linker consisting of hydrolysis-condensation products (MTMS1), the pure cross-linker (MTMS2) did not allow proper curing of uncovered samples regardless of thickness. The fact that MTMS 1 cross-linker allows curing of silicone elastomers in open air can be explained by a combination of following factors: 1) the hydrolysiscondensation reaction of MTMS (Figure 11) increases the number of reactive groups per molecule and therefore also per volume, resulting in a higher content of cross-linker reactive groups in the silicone elastomer premix than originally calculated; 2) the higher number of reactive groups per cross-linker molecule increases the probability of its reaction with HO-PDMS-OH before it has time to evaporate; 3 ) the MTMS1 cross-linker is less volatile due to the higher molecular weight of the hydrolysis-condensation products. 


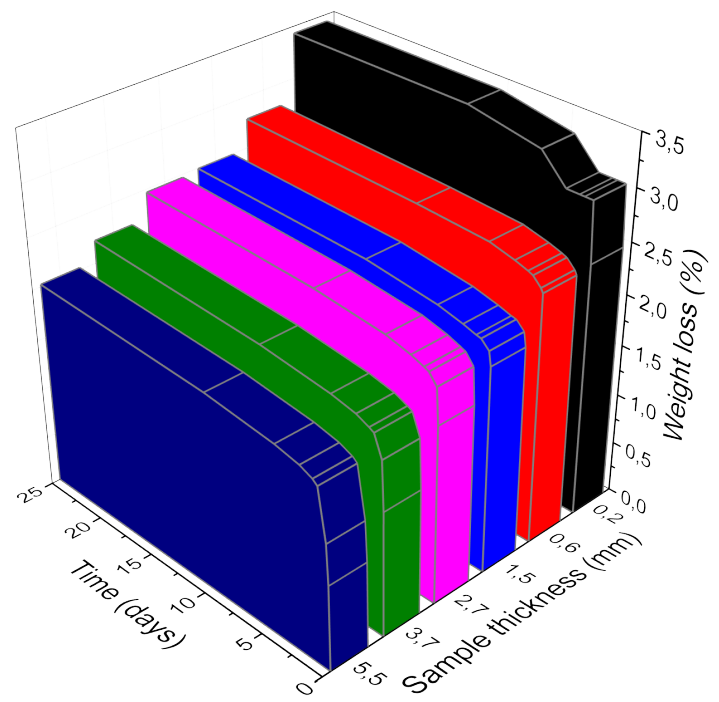

Figure 13: 3D plot of the dependence of sample weight loss over time on sample thickness. Sample thickness was varied from 0.2 to $5.5 \mathrm{~mm}$. The samples consisted of C2T, MTMS2 (2.5wt\%), and Sn catalyst $(1 \mathrm{wt} \%)$.

From the volatility experiments, it is clear that when using low molecular weight cross-linkers, the properties of the final elastomer are highly dependent on the cross-linker purity and sample thickness. In addition, small variations in sample preparation time and surrounding environment (e.g. temperature, pressure, and humidity) also influence the final concentration of the cross-linker in the elastomer and therefore contribute to poor reproducibility of the networks. The easily observed effects of the cross-linker purity, sample thickness and curing conditions on the elastomer properties are shown in Figure 14, where photos of samples prepared under different conditions illustrate significant changes in material performance. 


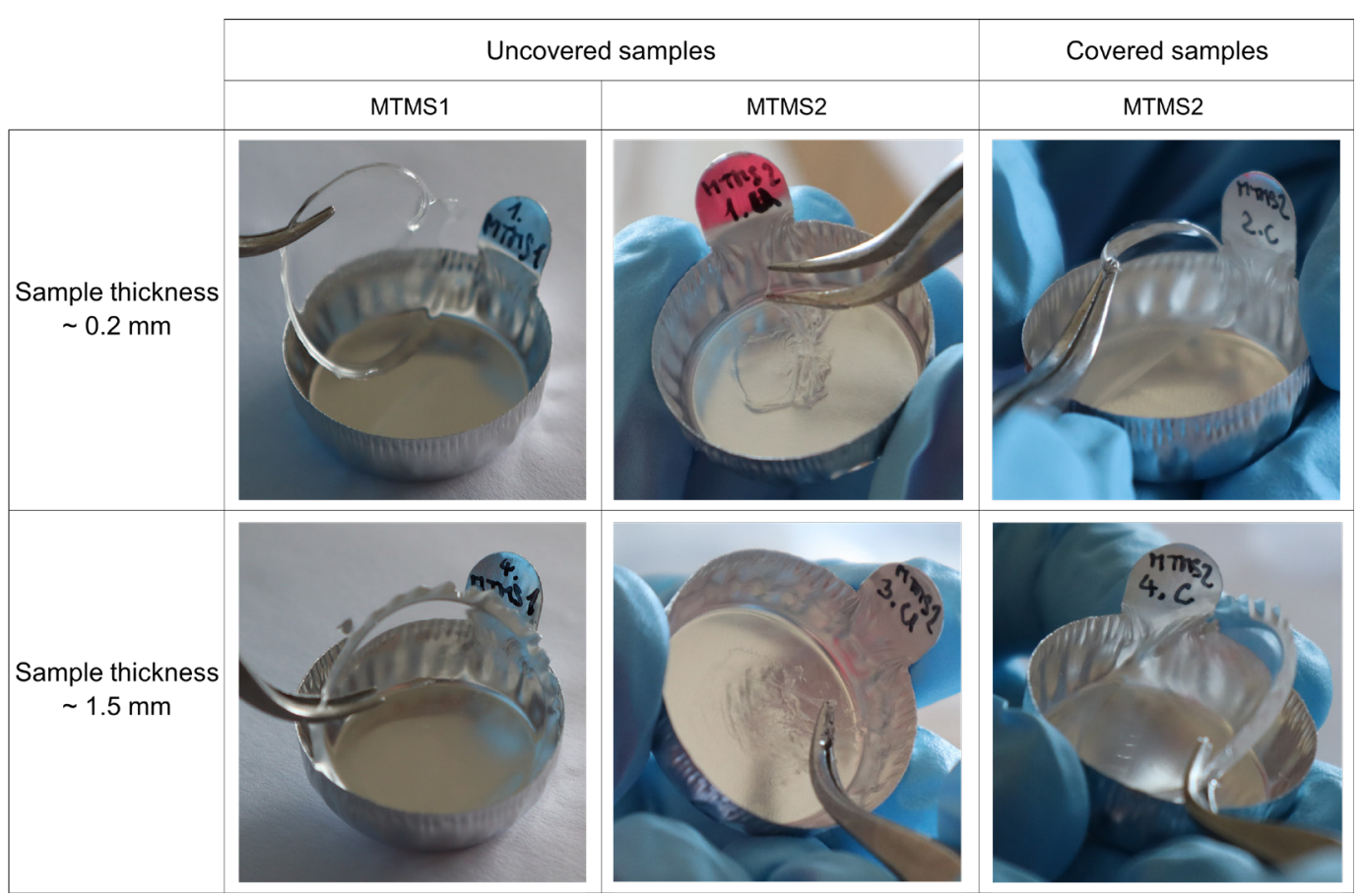

Figure 14: Photographic illustration of the effects of the MTMS cross-linker purity, sample thickness, and curing conditions on the elastomer properties.

\subsubsection{Tin catalyst concentration}

Tin catalysts used to cure condensation curing silicone elastomers can cause HO-PDMS-OH chains to undergo a condensation reaction. HO-PDMS-OH condensation in the presence of tin 2-ethylhexanoate was investigated by Clarson et al., ${ }^{18}$ who reported HO-PDMS-OH condensation if the catalyst was used in concentrations higher than $0.1 \mathrm{wt} \%$.

The condensation of HO-PDMS-OH influences the molecular weight between cross-links while simultaneously increasing the original stoichiometric ratio between the reactive groups of the cross-linker and the polymer. This can lead to the situation illustrated in Figure 9.1, where silica domains are created due to the reaction of the redundant cross-linker molecules. Furthermore, in the case of insufficient cross-linker concentration (Figure 9.2), the high concentration of tin catalyst will cause condensation of the dangling chains and unreacted chains, thereby creating more elastically active chains in the network. Theoretically, if the catalyst concentration is sufficiently large, a silicone network can be obtained without the use of a crosslinker due to the presence of concatenated rings (Figure 15). ${ }^{24,25}$ 

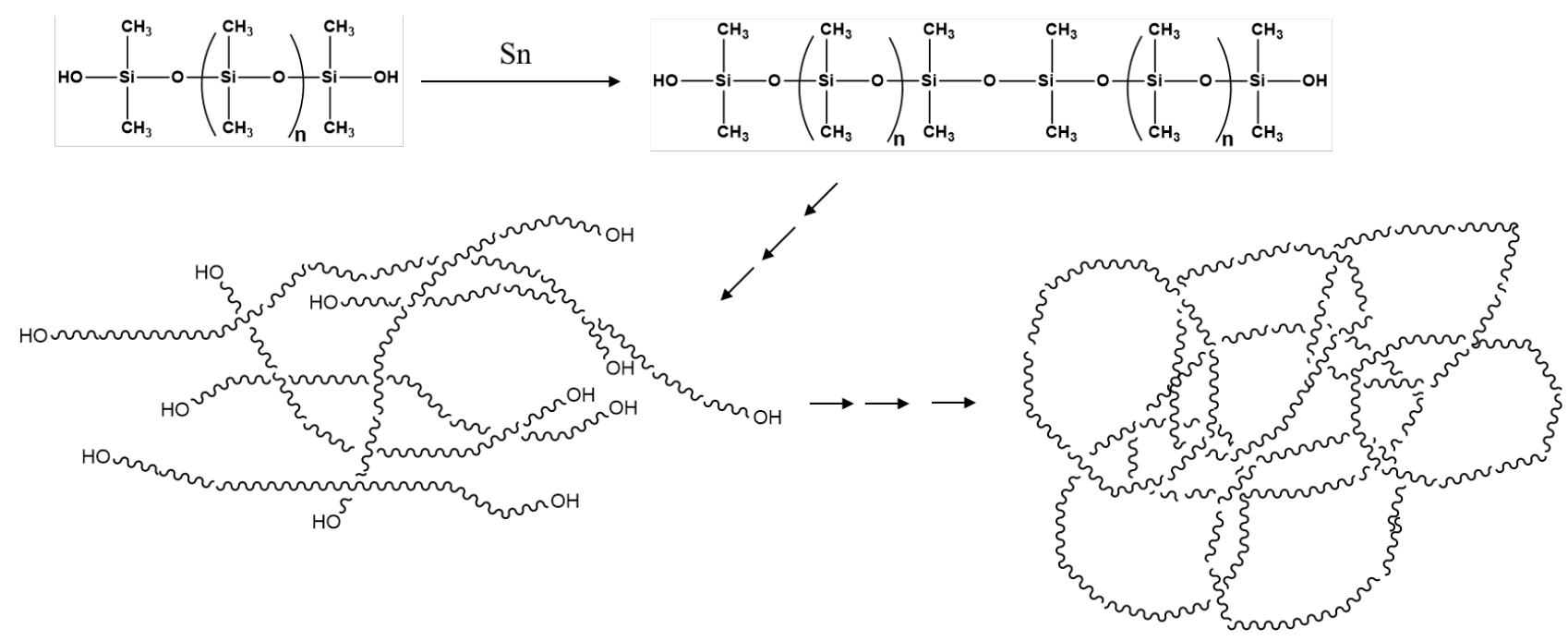

Figure 15: Condensation reaction between HO-PDMS-OH in presence of tin catalyst, which could theoretically create a network without the use of a cross-linker due to the presence of concatenated rings.

To investigate extent of HO-PDMS-OH condensation in our network formulation, five mixtures of C2T containing $0.05,0.1,0.5,1$, and $1.5 \mathrm{wt} \%$ of dibutyltin-diacetate, respectively, were prepared. The molecular weight of these mixtures over time showed that the condensation of $\mathrm{C} 2 \mathrm{~T}$ occurs for all Sn catalyst concentrations (Figure 16a). The reaction rate is then increasing with the increasing catalyst concentration as expected (Figure 16c). It should also be noted that as the average molecular weight $\left(\mathrm{M}_{\mathrm{n}}\right)$ increases, the polydispersity index (PDI) decreases. This decreasing PDI is attributed to the condensation mainly of low molecular weight fractions of the $\mathrm{C} 2 \mathrm{~T}$ polymer, which can be seen in the eluograms of Figure 16b. As mentioned previously, the condensation of HO-PDMS-OH in the presence of Sn catalyst influences the original stoichiometric ratio. Therefore, the optimum stoichiometric ratio depends also on the catalyst concentration, which poses another challenge for the formulation of silicone elastomer networks via condensation curing. 




b)

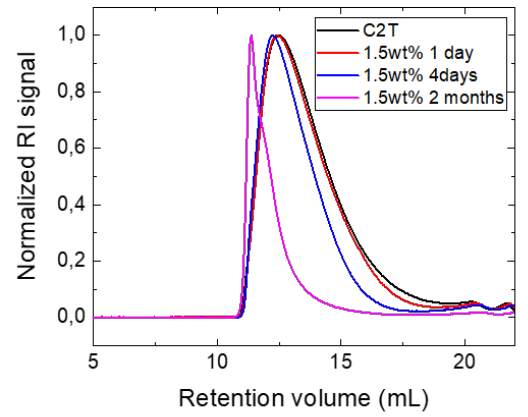

c)

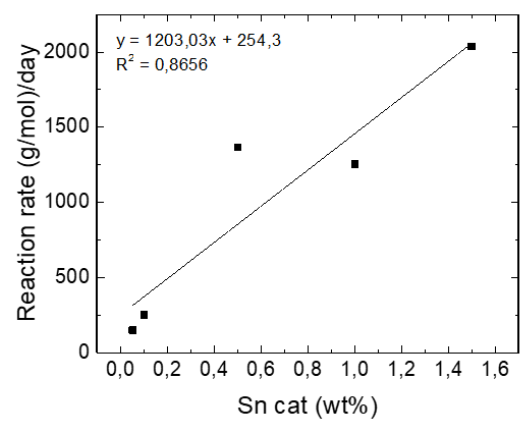

Figure 16: a) $\mathrm{M}_{\mathrm{n}}(\mathrm{g} / \mathrm{mol})$ and PDI over time of C2T containing $0.05,0.1,0.5,1$, and $1.5 \mathrm{wt} \%$ of Sn catalyst, respectively. b) Representative eluograms of $\mathrm{C} 2 \mathrm{~T}$ and $\mathrm{C} 2 \mathrm{~T}$ containing $1.5 \mathrm{wt} \%$ of Sn catalyst after 1 day, 4 days and 2 months. c) Reaction rates ((g/mol)/day) for the different $\mathrm{Sn}$ catalyst concentrations.

\section{Conclusion}

When creating different network structures in condensation curing silicone elastomers, several precautions regarding the network formulation are required due to the numerous side reactions occurring during the curing. The optimum stoichiometric ratio is influenced by both the reactions between the cross-linker molecules creating silica domains and the condensation of the HO-PDMS-OH increasing the molecular weight between the cross-links. This disables proper control over the network structure and contributes to strong post-curing effects, which we describe as a network instability. In addition, even though condensation curing silicone elastomers are readily cured at room temperature in open air, special attention must be paid to the selection of cross-linker. Low molecular weight cross-linker such as MTMS tend to evaporate from the silicone mixture before being reacted into the network structure, thus precluding open air curing. Furthermore, the cross-linker is prone to hydrolysis-condensation reactions. It was shown that the MTMS cross-linker where hydrolysis-condensation reaction took place (MTMS1) behaves significantly different from the one purchased in high purity (MTMS2). Therefore, in order to ensure longevity and reliability of the final condensation curing silicone elastomer products, following questions should be answered before choosing the type of the cross-linker: "What is the final application? Will the curing be done in open air or in 
a closed system? What is the required sample thickness?" If the final application requires a relatively thin silicone elastomer layer and at the same time does not allow curing under cover to prevent cross-linker evaporation prior to the curing reaction, higher molecular weight cross-linkers such as trialkoxy silanesterminated polysiloxanes or alkoxy-terminated polysilsesquioxanes should be used. Considering then the stability of the silicone network, a cross-linker concentration optimization study at given catalyst concentration should be done to find the composition in which the final silicone network changes the least over time.

\section{Acknowledgement}

The authors would like to acknowledge the Hempel Foundation to CoaST for financial support.

\section{References}

1. Lacour SP, Jones J, Wagner S, Li T, Suo Z. Stretchable Interconnects for Elastic Electronic Surfaces. Proc IEEE. 2005; 93(8): 1459-1467.

2. Larmagnac A, Eggenberger S, Janossy H, Vörös J. Stretchable electronics based on Ag-PDMS composites. Sci Rep. 2014; 4: 1-7.

3. Mashak A, Rahimi A. Silicone Polymers in Controlled Drug Delivery Systems: A Review. Iran Polym J. 2009; 18(4): 279-295.

4. Van Den Kerckhove E, Stappaerts K, Boeckx W, et al. Silicones in the rehabilitation of burns: a review and overview. Burns. 2001; 27: 205-214.

5. Haas HE, Kovacs FL. Oil resistant silicones, U.S. Patent 6,413,354 B1. 2002.

6. Riegler B, Bruner SJ, Elgin R. Optical silicones for use in harsh operating environments. Proc SPIE. 2004; 5590: 140-151.

7. Low DKY, Li L, Byrd PJ. Spatter prevention during the laser drilling of selected aerospace materials. J Mater Precessing Technol. 2003; 139: 71-76.

8. Eduok U, Faye O, Szpunar J. Recent developments and applications of protective silicone coatings: A review of PDMS functional materials. Prog Org Coatings. 2017; 111: 124-163.

9. Madsen FB, Daugaard AE, Hvilsted S, Skov AL. The Current State of Silicone-Based Dieletric Elastomer Transducers. Macromol Rapid Commun. 2016; 37: 378-413.

10. Madsen FB, Daugaard AE, Fleury C, Hvilsted S, Skov AL. Visualisation and characterisation of heterogeneous bimodal PDMS networks. RSC Adv. 2014; 4(14): 6939-6945. 
11. Genesky GD, Aguilera-Mercado BM, Bhawe DM, Escobedo FA, Cohen C. Experiments and simulations: Enhanced mechanical Properties of end-linked bimodal elastomers. Macromolecules. 2008; 41(21): 8231-8241.

12. Bejenariu AG, Yu L, Skov AL. Low moduli elastomers with low viscous dissipation. Soft Matter. 2012; 8(14): 3917-3923.

13. Mazurek P, Vudayagiri S, Skov AL. How to tailor flexible silicone elastomers with mechanical integrity: A tutorial review. Chem Soc Rev. 2019; 48(6): 1448-1464.

14. Forzatti P, Lietti L. Catalyst deactivation. Catal Today. 1999; 52(2-3): 165-181.

15. Cranstoun GKL. Metallic catalysts. Nature. 1976; 259(5539): 162-162.

16. Stein J, Burnell TB. Sprayable, condensation curable silicone foul release coatings and articles coated therewith, U.S. Patent 5,904,988. 1999.

17. Van Den Weij FW. The Action of Tin Compounds in Condensation-type RTV Silicone Rubbers. Makromol Chem. 1980; 181: 2541-2548.

18. Clarson SJ, Wang Z, Mark JE. Effect of stannous 2-ethylhexanoate on the network formation and chain extension reactions of $\alpha, \omega$-dihydroxy terminated poly(dimethylsiloxane). Eur Polym J. 1990; 26(6): 621-622.

19. Robinson MWC, Swain AC, Khan NA. Influence of cross-linker and tin (II) bis-2-ethylhexanoate on compression set characteristics of poly(dimethylsiloxane) elastomer networks. Polym Degrad Stab. 2015; 116: 88-93.

20. Kimura T, Ikeno M. Room temperature fast curable compositions, U.S. Patent 6,306,998 B1. 2001.

21. Sprung MM, Guenther FO. The Partial Hydrolysis of Methyltrimethoxysilane. J Am Chem Soc. 1955; 77(15): 4173-4175.

22. Smith KA. Polycondensation of Methyltrimethoxysilane. Macromolecules. 1987; 20: 2514-2520.

23. Issa AA, Luyt AS. Kinetics of Alkoxysilanes and Organoalkoxysilanes Polymerization: A Review. Polymers (Basel). 2019; 11(3): 537.

24. Fischer J, Lang M, Sommer JU. The formation and structure of Olympic gels. J Chem Phys. 2015; 143.

25. Jacobson H, Stockmayer WH. Intramolecular reaction in Polycondensations. I. The theory of linear systems. J Chem Phys. 1950; 18(1600). 